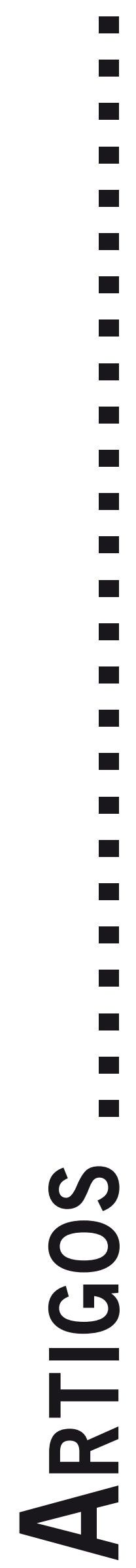




\title{
FORMAS DE EXERCER A PATERNIDADE EM BELÉM E ÉVORA
}

\author{
Forms of to Exert the Paternity in Belém and Évora \\ Forma de Ejercer la Paternidad en Belém y Évora
}

Adelma Pimentel

\begin{abstract}
Resumo: As formas de exercer a paternidade no mundo estão se modificando. Convivem na mesma cultura modelos tradicionais e tentativas de construir uma nova identidade para o pai. Brasil e Portugal são dois paises cuja formação cultural do homem ainda é marcada por orientações de gênero patriarcais que imprimem forte atuação do homem em funções menos participativas na família o que repercute no distanciamento afetivo e na educação dos filhos. Este horizonte fundamentou a realização da pesquisa qualitativa exploratória realizada em Belém (Pará, Brasil) e em Évora (Portugal), procurando delinear algumas características das formas que o pai brasileiro e o português exercem a paternidade. Objetivo: Identificar a autopercepção da paternidade focalizando modelos, funções, valores e a concepção de amor dos informantes. Procedimentos: Aplicação individual de 89 questionários, 70 em Évora e 19 em Belém a pais de crianças do jardim de infância. As análises focalizaram o singular e o intersubjetivo. Entre os resultados encontramos: presença do sentido de pater como nutritor, isto é, os pais tiveram a intenção de conceber o filho e formar com eles um vínculo estável; o estado civil (casado ou união estável) não significa que há uma participação conjunta com a mãe no cuidado com os filhos, ou seja, no desenvolvimento emocional saudável que requer a presença do pai ou pelo menos a qualidade da convivência.

Palavras-chave: Percepção; Funções Paternas; Modelos.
\end{abstract}

Abstract: The form of exert the paternity in the world is modifying itself. However living together in the same culture traditional and attempt of the establishing a new identity for the father. Brazil and Portugal are two countries whose the man's cultural formation is still marked by patriarchal gender orientations that they set a strong performance of the man in functions less participation in the family, what resound in the affectionate estrangement and in the children's education. This horizon based the accomplishment of the exploratory qualitative research accomplished in Belem, Para, Brazil and in Ever, Portugal, trying to delineate some characteristics in the ways that Brazilian and the Portuguese fathers exercise the paternity. Objective: To identify the self-perception of the paternity focusing models, functions, values and the conception of love of the informers. Procedures: Application of 89 questionnaires: 70 in Évora and 19 in Belem to the fathers of the children's in kindergarten. Analyze were focalized for the singular and the intersubjetive. in the results we found: presence of the pater sense as nutritor, that is, the parents had the intention of to conceive the son and to form with them a stable entail; the civil status (married or stable union) it doesn't mean that there is an united participation with the mother in the care with the children, in other words, in the healthy emotional development that requests the father's presence or at least the quality of the coexistence.

Keywords: Perception; Paternal Functions; Models.

Resumen: Las formas de ejercer la paternidad en el mundo están se modificando. Convivir en la misma cultura modelos tradicionales y tentativas de construir una nueva identidad para el papá. El Brasil y Portugal son dos países cuya formación cultural del hombre, hasta ahora, es marcada por orientaciones de género patriarcales que imprimen fuerte actuación del hombre en funciones menos participativas en la familia, lo que repercute en el distanciamiento afectivo y en la educación de los hijos. Este horizonte fundamentó la realización de la pesquisa cualitativa exploratoria efectuada en Belém, Pará, Brasil e en Évora, Portugal, buscando delinear algunas características de las formas que el papá brasileño y o portugués ejercen la paternidad. Objetivo: Identificar la auto percepción de la paternidad enfocando modelos, funciones, valores y la concepción del amor de los informantes. Procedimientos: aplicación individual de 89 cuestionarios: 70 en Évora y 19 en Belém a los papás de niños del jardín de infancia. Las análisis enfocaran el singular y o intersubjetivo. Entre los resultados encontramos: presencia del sentido de pater como nutritor, esto es, los papás habían tenido la intención de concebir y formar con ellos un vínculo estable; lo estado civil (casado o unión estable) no significa que ha una participación conjunta con la madre en lo cuidado con los hijos, o sea, en lo desenvolvimiento emocional saludable que requiere la presencia del papá o pelo menos la cualidad dela convivencia. Palabras-clave: Percepción; Funciones Paternas; Culturas.

\section{Introdução}

O exercício da política e a herança são as marcas da configuração da paternidade romana, de modo que o genitor (biológico) é uma figura desprovida de valor. Hurstel
(1999) afirmou que o Direito Romano é o embrião da concepção de paterfamilias ligada não à base biológica da paternidade, mas a vida na polis,

Zoja (2005) recuperou o sentido da palavra pai derivado de pater: o nutritor. $\mathrm{O}$ autor se valeu do mito grego 
para diferenciar o pai do genitor, figura formal criada em Roma, a partir do século II d.C., para introduzir a obrigação de dar alimento a quem é colocado no mundo.

Para ser pai não basta saber o que é o pai: é necessário conhecer o filho e a relação com ele... Heitor retira o elmo. Formulando um augúrio para o futuro, ergue o filho com os braços e com o pensamento. Esse gesto será por todos os tempos a marca do pai (p. 84).

Considerou, ainda, que a função biológica e afetiva do pai são proferidas pelo homem que conscientemente eleva $^{1}$ o filho gerado e assumido.

Em nossos atendimentos na clínica-escola percebemos que cada vez mais o pai, por vários motivos, está ausente do mundo interno que remete ao desenvolvimento emocional e social dos filhos. Destarte, a paternidade reflete as diversas crises que a cultura ocidental engendra: da família, das subjetividades, das representações políticas em todas as esferas do poder, etc. Entender a crise da paternidade requer focalizar alguns pontos que a configuram. Por exemplo: autoridade, reduzida pela inserção de novas figuras masculinas no universo psicológico das identificações que os filhos necessitam para subjetivação masculina; instabilidade do papel, instituída pelos novos provedores de recursos: mãe, filhos, etc

Para Lamb (1997, citado por Crepaldi et al., 2006), o contato entre pai e criança ocorre em maior escala física, aumenta com a idade e tende a ser mais intenso em locais públicos. Cabrera e cols. (2000, citados por Crepaldi et al., 2006) ainda ressaltam que as mães, comparadas aos pais, frequentemente dão mais cuidado, proteção e conforto. Por outro lado, o pai é mais responsável pelo papel instrumental na família, ligando a criança à sociedade (Crepaldi et al., 2006).

Trindade (1998) estudando os modelos de paternidade codificou três: patriarcal, "baseado em um sistema social e econômico agrícola. O pai tinha poder total sobre os filhos" (p. 132); moderno (atual), "surgido com a sociedade industrial... O pai perdeu poder como autoridade rígida, mas aumentou seu valor como condutor moral" (p. 133), e andrógino de paternidade, "estilo baseado no princípio de igualdade, tanto nas responsabilidades e na valorização das expressões emocionais e afetivas” (p. 133). Cia, Williams \& Aiello (2005) revisando literatura identificaram três modelos de paternidade: tradicional, moderna e emergente. O modelo patriarcal descrito por Trindade (1998) contém alguma semelhança com o tradicional proposto por Cia et al. (2005); por exemplo, ambos apontam o papel de provedor como a função principal exercida pelo pai. As diferenças estão nos modelos que os autores su-

\footnotetext{
Suscipere: elevar: verbo. $\mathrm{O}$ ato de elevar fisicamente uma criança no ar por um instante significava transferi-la social e moralmente para um plano mais alto para toda a sua vida. Esta era a escolha do pai: um dom de vida social e moral para o filho (Zoja, 2005, p. 153).
}

gerem representar uma renovação das funções paternas: Trindade (1998) assinalou a categoria andrógina, enquanto Cia et al. (2005) a nomearam de emergente. Em ambas está contida a referência à ampliação da valorização da expressão emocional do pai.

Os limites que os homens podem vivenciar quando iniciam a paternidade; estabelecem laços com os filhos e são solicitados a expressar os afetos; dificuldades em ser pai, são problemas que vão aumentando conforme os filhos crescem. São temáticas estudadas por (Rohde et al., 1991; Bizarro, 2006; Suassuna, 2006).

O modo como os pais tratam as crianças depende muito do sexo a que elas pertencem: os meninos/rapazes são encorajados a tornar-se independentes, ambiciosos, etc., e as meninas/raparigas devem mostrar-se amáveis, generosas, atraentes, etc.

Estas pesquisas corroboram o que Zoja (2005) assegurou que caracteriza o pai hoje: que é estavelmente deprimido, isto é, perdeu o interesse pelo trabalho e também uma grande parte da sua relação concreta com a família.

Em Portugal, atualmente, de acordo com Mendes (2007), os pais afirmam querer ter um papel mais ativo, efetivo e interventivo, em contraposição aos modelos de paternidade vivenciados ou observados em gerações anteriores.

Esse autor entrevistou trinta pais de 20-35 anos da área metropolitana de Lisboa e criou uma tipologia (não rígida) para agrupar as vivências da paternidade.

Pai formiga: os filhos são inesperados, tem maior investimento profissional. (...) Instrumentalização dos recursos econômicos na criação de condições para uma educação considerada "boa”. (...) Apresentam uma menor disponibilidade e orientação para a família (...) Responsabilizam as mulheres pelos cuidados e educação dos filhos; Pai galinha: reconhecimento da importância de estar presente na vida dos filhos, desenvolvendo uma relação emocional com estes. São os que mais participam nas práticas e cuidados relacionados com os filhos. (...) Pai galo: posicionamento mais conservador perante o desempenho efectivo do papel de pai e face ao papel da mulher na família e na sociedade. (Mendes, 2007, pp. 19-20)

Balancho (2003) entrevistou na região da grande Lisboa pais, avós e filhos buscando identificar nas três gerações uma percepção atual do pai português.

Para pais e filhos da actualidade, o pai é, sobretudo amor e afecto, depois educador e finalmente brincalhão. As suas funções são inequívocas e bem delimitadas a estes domínios. Ser gerador de vida ou ganha-pão é característica que nenhuma (ou pouca) importância tem para pais e filhos de hoje, ainda que continue relevante na forma da geração dos avôs de- 
finirem a paternidade. Estes últimos definem-na com um âmbito mais alargado, incluindo a importância na transmissão de valores, na disciplinação, na expressão afectiva, na brincadeira e no apoio econômico. O novo filho, agora pai, educado já na era mais permissiva dos anos 60 e 70, não receia tanto as ameaças à sua masculinidade que podem advir de ser mais dedicado à família, mais terno e mais acessível, mais expressivo e mais liberto. É muito claro, pelas conclusões deste estudo, que o novo homem veio pôr em causa o anterior. (Balancho, 2003, pp. 88-89)

Estas asserções ilustram que convivem na sociedade portuguesa, regiões do Alentejo e na grande Lisboa, práticas educativas mais autoritárias que advém de um perfil tradicional de pai e práticas de reconstrução da identidade paterna.

Trindade (1998) e Cia et al. (2005) sugerem que a ausência, a rarefação e o declínio da importância do pai estão presentes em todas as sociedades ocidentais variando conforme a classe socioeconômica: o pai pobre e indigno, geralmente esta ausente pelo desinteresse e incompreensão mútuos: família e si mesmo; os pais remediados e ricos, também indignos, não estão presentes devido à facilidade do divórcio e pela complexidade do trabalho que requer viagens de negócios, reuniões.

Neste estudo qualitativo exploratório, focalizamos a autopercepção da paternidade (Pimentel, Frazão \& Franco, 2007), os modelos, as funções, valores e a concepção de amor de pais que vivem em Belém do Pará e em Évora, respectivamente, cidades brasileira e portuguesa. As cidades apontadas correspondem aos locais de atuação dos pesquisadores. Antes de apresentar os resultados da investigação situamos brevemente o contexto geográfico onde ocorreu a pesquisa:

Santa Maria de Belém do Grão Pará, Belém, é a capital do estado do Pará localizado na região Norte do Brasil. É uma cidade de gente hospitaleira, considerada o portal da Amazônia. Ocupa uma área de 51.600 ha, onde mais da metade representam ilhas. Fundada em 12 de janeiro de 1616 pelo Capitão-Mor Francisco Caldeira Castelo Branco, quando foi construído, no encontro dos rios Pará e Gama, na elevação chamada pelos índios Tupinambás de Mairi, um forte de madeira, coberto de palha, denominado Forte do Presépio, redenominado Forte do Castelo e atualmente Feliz Lusitânia. Convivem harmoniosamente a cidade moderna e a arquitetura secular de origem nitidamente portuguesa, com um toque do neoclássico francês (Duarte, 2007).

Évora é uma urbe medieval, cujas muralhas estão repletas de portas que permitem ao visitante adentrar nos vários sítios repletos de história. Capital do Alto Alentejo é sede de Concelho, Distrito, Comarca, Arquidiocese, Relação e Região Militar e situa-se a 130 km de Lisboa. Tem mais de 50.000 habitantes, que se dedicam às indústrias de cortiça, cerâmica, curtumes, produtos ali- mentares e agropecuária. A cidade foi classificada como Patrimônio da Humanidade em 1986 pela UNESCO (Câmara Municipal de Évora, 2007; Symington, 2007).

\section{Metodologia}

A pesquisa realizada em Belém (Pará, Brasil) e em Évora (Portugal) foi de cunho qualitativo exploratória. Esta abordagem expressa a possibilidade que o pesquisador tem de compreender melhor a manifestação geral de um problema, as ações, as percepções, os comportamentos e as intenções das pessoas relacionadas à situação específica. Nesta perspectiva de investigação tem relevo o desvelamento dos significados que as pessoas atribuem as suas ações (Lessard-Hébert, Goyette, \& Boutin, 2005). Além disso, Goldenberg (2003) considera que a condução de uma pesquisa qualitativa depende, dentre outras coisas, da biografia do pesquisador, de suas opções teóricas, do contexto mais amplo e das imprevisíveis situações que ocorrem no dia-a-dia. O delineamento visou identificar: a) algumas características das formas que o pai brasileiro e o português exercem a paternidade; b) autopercepção da paternidade focalizando modelos, funções, valores e a concepção de amor dos informantes. Devido ao caráter internacional da pesquisa submetemos o projeto da investigação aos Comitês de Ética em pesquisa da UFPA e da Universidade de Évora. Foram critérios de participação: ter pelo menos um filho biológico freqüentando um nível de educação pré-escolar; conhecer as normas e objetivos do projeto assinando o consentimento de investigação.

A equipe de pesquisadores aplicou questionários em Évora na Creche Quinta dos Sonhos², estabelecimento da rede privada de pertença a Seguridade Social, e na Associação da Creche e Jardim de Infância de Évora, instituição privada de solidariedade social, com estatuto de utilidade pública; e, em Belém, em uma creche particular e na escola mantida pela Universidade Federal do Pará.

O questionário continha perguntas abertas cujas categorias de resposta foram agrupadas em: concepção de paternidade, os modelos, as funções, os valores (éticosmorais) e as práticas amorosas. Duzentos questionários foram entregues nas duas cidades, porém apenas oitenta e nove foram analisados, já que setenta foram devolvidos por pais da cidade de Évora, e dezenove por pais da cidade de Belém. A diferença entre o volume de informantes ${ }^{3}$ se deveu, especificamente, a colaboração dos informantes: em Évora a direção das instituições envolveu as professoras das turmas indicadas na aplicação e acompa-

\footnotetext{
As instituições citadas autorizaram por escrito a divulgação das mesmas bem como o projeto foi aprovado em comitês de ética nas duas cidades.

3 Vale ponderar que durante a realização de um projeto de pesquisa qualitativa estamos envolvidos na cotidianeidade dos acontecimentos, o que requer ao pesquisador organizar adaptações ao curso do projeto, bem como ampliar a preocupação com a devolução aos participantes do estudo das conclusões elaboradas no relatório.
} 
nhamento da devolução dos formulários; enquanto que em Belém, houve apenas autorização institucional para a pesquisadora e equipe de alunos coletarem material. Em uma semana de visita a escola, tivemos que lidar com fatores como: "esquecimento" dos pais em devolver o formulário; reduzido tempo dos mesmos, e falta de atenção das professoras no acompanhamento da pesquisa, face ao grande número de crianças para cuidar.

O perfil da amostra foi: estado civil: Évora: 8,5\% dos pais se declararam 'divorciado', enquanto 10,6\% de Belém alegaram ser ‘casado/separado' ou ‘separado da primeira esposa'; 7,1\% (Évora) e 26,3\% (Belém) afirmaram que eram 'solteiro'; 81,4\% (Évora) e 63,2\% (Belém) se declararam ‘casado’ ou em ‘união/relação estável'; e 2,9\% (Évora) não declararam seu estado civil; 81,4\% dos pais eborenses e $73,7 \%$ dos belenenses ${ }^{4}$ assumiram viver com os filhos e a mãe dos mesmos. No que se refere ao tratamento dos dados, a perspectiva qualitativa permitiu identificar a partir das perguntas do questionário categorias abrangendo tanto peculiaridades das informações como manifestações intersubjetivas dos dados. Sempre que possível, associei os dados aos achados teóricos temáticos visando formar uma conclusão acerca dos sentidos gerais; refletir e interpretar as significações desveladas.

\section{Resultados e Discussão}

\section{1) Concepção de Paternidade}

Para os pais eborenses através da afetividade podem dar amor, afeto, ser amigo, companheiro, preocupar-se, ser cioso, brincar; enquanto que na dimensão moralidade ser "bom" e disciplinar são as qualidades características. Como autodescrição, destacamos a adjetivação "pai galinha”, aquele que reconhece a importância de estar presente na vida dos filhos, desenvolvendo uma relação emocional com estes, convergindo com os estudos de Mendes (2007). Para os pais belenenses, destacamos as classes educar, prover, dialogar e atualizarem-se como aspectos singulares das informações contidas na amostra. Em comum, os pais belenenses e os eborenses se preocupam em serem afetivos, presentes, cuidadores, e discipliná-los, quando necessário.

\section{2) Os Modelos}

Os pais eborenses afirmaram que seus modelos de paternidade foram: não afetivo, ou distante, ausente, autoritário, seco e frio, pouco tolerante, muito rígido, austero; não-amoroso e desrespeitoso; muito fechado, austero; agente moral, ou rigoroso, disciplinador, com pouco diálogo; amoroso, amigo, atencioso, conselheiro, cuidadoso; presente; brincalhão; paciente; alguém com quem se pode contar; provedor, honesto, trabalhador, chefe de família; exemplo, um modelo a repetir.

\footnotetext{
Segundo casamento.
}

Os pais belenenses descreveram seus modelos nas categorias: mito, o herói; agente moral, disciplinador; ético; repreensivo, quando necessário; provedor, ou trabalhador, dedicado, responsável:; honesto, educado, sincero; profissional e chefe de família; não afetivo, alguém nunca presente; amoroso, divertido, brincalhão, amigo; ótimo pai; carinhoso; grande homem e grande caráter; companheiro amigo, presente; limitado na família, um pouco rude devido à falta de oportunidade para receber educação formal e familiar. Em síntese, as qualidades autodescritas sugerem dois modelos de paternidade: 1) mítico, em que o pai apresenta mais as qualidades do herói que do homem; 2) tradicional, respondendo pelo sustento material e distanciamento afetivo (Pimentel \& Franco, 2005; Pimentel, 2007).

\section{3) Diferenças entre os modelos e a forma do informante exercer a paternidade}

Todos os pais eborenses e belenenses usaram o advérbio mais para destacar a marca da diferenciação entre eles e seus pais. Identificaram-se enquanto homens de seu tempo ressaltando o esforço realizado para serem distintos; talvez para superar as lacunas deixadas pelos seus pais, principalmente nas áreas afetiva e dialógica. Assim, autorreferem-se como mais afetivos, presentes, democráticos, dialógicos em comparação aos seus próprios pais.

\section{4) Funções cotidianas}

Destaque para cuidar do bem-estar físico dos filhos e filhos e realizar atividades objetivas: higiene corporal, cuidar, educar, lúdicas, alimentar e prover. Destas, a educação foi destaque. Embora todos os pais que constituíram a amostra trabalhem a função de prover não foi evidenciada; talvez pela intensa participação da mãe que trabalha fora na composição da renda familiar. As respostas destacaram a preocupação dos pais com o aspecto do asseio corporal, talvez uma atitude relacionada aos aspectos da prevenção de adoecimento do filho o que lhes exigiria recursos financeiros adicionais. De modo singular um pai belenense evidenciou uma preocupação com a formação religiosa do filho, esta indicação nos chama atenção já que no contexto mundial há duas perspectivas convivendo: por um lado repudio ao cultivo de cultos etnocêntricos permitindo que as diversas formas de religião sejam desenvolvidas; por outro, espelha uma crise da esperança caracterizada pela preconização da morte do transcendente e da crença em Deus. Portanto, parece que este pai ao assegurar que é sua função fornecer uma base de fé através da ida à igreja com o seu filho fortalece os seus vínculos com a esperança.

\section{5) Valores que integram o sistema ético}

Identificamos alguns valores que parecem integrar a concepção e talvez o sistema ético-moral para orientar as relações sociais dos informantes. Os pais belenenses e eborenses afiançaram a importância da integridade, ho- 
nestidade, dignidade e responsabilidade; senso de coletividade, que adita a amizade, a solidariedade, a importância da justiça e do outro. Estas respostas sugerem a significação de apontar normas para fundamentar a ação ética dos filhos e filhas integrantes das sociedades eborense e belenense. Portanto, é possível considerar que os informantes resistem e criticam as ações veiculadas em todas as mídias sobre os valores antiéticos praticados pelos representantes do povo nas câmaras legislativa portuguesa e brasileira, em que alguns legisladores se valem do cargo para auferir benefícios pessoais ferindo os códigos éticos. Do ponto de vista da singularidade destacamos que os pais eborenses reiteram a importância da intimidade; enquanto que de um pai belenense que mencionou "não sei o que ensinar a uma criança de 04 anos", nos pareceu precisar de suportes emocionais para o exercício da paternidade. Pela condição de separado da mãe do filho, sua participação é limitada, além disso, as fronteiras da aprendizagem na formação da subjetividade masculina interferem nos modos de comunicar, expressar a afetividade, solicitar ajuda; aliados as típicas atitudes de impedir o relacionamento pai e filho que algumas mulheres tomam quando se separam, configurando a instalação da padrectomia ${ }^{5}$.

\section{Considerações Finais}

Este foi um estudo exploratório realizado para delinear algumas funções que os pais brasileiros e portugueses vêm realizando. A temática faz parte de nossos estudos acerca da masculinidade. De semelhante entre as concepções e práticas da paternidade apresentadas pelos informantes de Belém e Évora, observamos:

a) Presença do sentido de pater como nutritor, isto é, os pais tiveram a intenção de conceber o filho e formar com eles um vínculo estável;

b) $68,2 \%$ dos pais belenenses e $81,4 \%$ dos eborenses afirmaram que são casados ou vivenciam união estável. Talvez a vida em comum signifique uma participação com a mãe no cuidado com os filhos, bem como um indicador da tentativa de superação da dificuldade da expressão emocional do pai;

c) o exercício da higiene corporal, brincar, passear, levar a escola sugere que há uma maior participação do pai na facilitação e acompanhamento do crescimento e desenvolvimento lúdico dos filhos.

Acerca da concepção de paternidade tanto em Belém como em Évora a autodescrição dos informantes sugere que vivenciam a paternidade de maneira a exercer suas funções de modo galinha, ou seja, são carinhosos, presentes, envolvidos, etc. Sobre a demonstração de amor esta é pautada na afabilidade, nos atos físicos de beijar, abraçar,

\footnotetext{
${ }^{5}$ A esse respeito ver Martinez, 2006.
}

tocar o filho de modo carinhoso; na dedicação incondicional e diálogo. De maneira singular, os pais eborenses incluíram o aspecto financeiro referindo-se a importância de nada faltar ao filho; enquanto que os pais belenenses destacaram a religiosidade. Esta ênfase à devoção talvez seja explicada pelos diferentes valores que a religião católica assumiu no Sul de Portugal: os Alentejanos não são religiosos como os habitantes do Norte de Portugal, enquanto que os Belenenses ${ }^{6}$ são devotos da Senhora de Nazaré, e na cidade, durante o ano inteiro, se dá a preparação para o Círio que ocorre a duzentos anos no mês de outubro, em homenagem a mãe de todas as mães.

Em ambas as cidades, de modo geral, percebemos que as funções e tarefas do Pai cuidadoso, ainda, são minimamente descritas, portanto não apontam a transcendência da pratica clássica do modelo de pai provedor. Acerca da ética, os achados sugerem que as orientações paternas ensinam referências que privilegiam a interação, a relação dialógica e a importância da coletividade estabelecem uma base para que os filhos, talvez, possam contribuir para a transformação social que fomenta um projeto humano de reconfiguração dos laços afetivos entre os membros da família.

Morin (2005) desenvolve a idéia de uma autoética desdobrada em ações para si mesmo e para o outro, abrangendo respectivamente, autoanálise, autocrítica, tolerância, prática da recursão ética, luta contra a moralina, resistência a lei de talião e ao sacrifício do outro, tomada de responsabilidade; consciência da complexidade e dos desvios humanos, abertura à magnanimidade e ao perdão, ética da compreensão, da cordialidade e da amizade.

Os pais revelaram que é importante para o desenvolvimento emocional dos filhos contribuírem para que estes fortaleçam o amor próprio e a autoestima. Tais orientações, no plano subjetivo ou do psiquismo, talvez, contribuam para que, especialmente os meninos reformulem o exercício da paternidade integrando-se as funções de cuidado primário.

Em tempos de globalização e rupturas foi importante descobrir que os pais portugueses se preocupam com a manutenção do sentimento de nacionalidade, respeito e apreciação do País em que vivem; dão muita importância para a vida em família cultivando a intimidade, alegria, felicidade. A despeito das transformações que as sociedades ocidentais, no âmbito do local e do global, vêm sofrendo, estes dados apontam, para a importância do pai e do exercício de uma paternidade ética, o que considero um suporte indispensável à atualização do desenvolvimento e aprendizagem infantil. Não há receitas para ser pai, há intencionalidades, projetos e atos, boa vontade e, sobretudo amor, por si e pelo outro. Os pais brasileiros e portugueses parecem empenhados em não praticar apenas o princípio da paternidade romana, isto é da ênfase ao direito biológico ou a adoção.

\footnotetext{
${ }^{6}$ Falamos da população em geral não especificamente da devoção dos pais.
} 
As transformações psicológicas e sociais vêm ocorrendo mais no âmbito do papel do homem que no do pai (Carvalho, 2006) Talvez, uma decorrência do processo de socialização dos meninos que continua marcado por um conjunto de orientações e adjetivações que contribuem para formar um molde idealizado de masculinidade: tem que ser forte, confiante, ativo, destemido, determinado, realizador, independente, objetivo, pragmático, racional, emocionalmente equilibrado, profissionalmente competente, financeiramente bem sucedido e sexualmente impositivo, dominador, violento, opressor. (Wang, Jablonski, \& Magalhães, 2006).

A socialização e a educação são tarefas da ordem do público e do privado; assim, consideramos imprescindível a articulação entre políticas educacionais e as orientações disseminadas nas redes familiares pelos pais, mães e cuidadores, de modo a permitir a atualização dos princípios contidos na transmissão da socialização de gêneros e dos processos de subjetivações masculinas.

\section{Referências}

Balancho, L. F. (2003). Ser pai, hoje. Lisboa: Ed. Presença.

Bizarro, S. (2006). A angústia da paternidade. Intelecto [online], 5. [Citado 11 outubro 2006]. Disponível em: www.geocities. com/revistaintelecto/paternidade.html?2006.

Câmara Municipal de Évora. Acesso em 11/12/2007, em www. cm-evora.pt/.

Carvalho, Maria Luiza de. (2006). Homem tem jeito para cuidar de criança?. Acesso em 11.10.2006, em www.pailegal.net/.

Cia, W., Williams, L., \& Aiello, A. (2005). Influências paternas no desenvolvimento infantil: Revisão da literatura. Psicologia Escolar e Educacional, 9 (2), 225-233.

Crepaldi, M. A., Andreani, G., Ristoff, C. D., Hammes, P. S., \& Abreu, S. R. de. (2006). A participação do pai nos cuidados da criança, segundo a concepção de mães. Psicologia em Estudo, 11, 579-587.

Duarte, A. (2007). Revista Ver-o-Pará, 7. Belém: Ed. Círios.

Goldenberg, M. (2003). A arte de pesquisar: Como fazer pesquisa qualitativa em Ciências Sociais (7. ed.). Rio de Janeiro: Record.

Hurstel, F. (1999). As novas fronteiras da paternidade. Campinas, SP: Papirus.

Lessard-Hébert, M., Goyette, G., \& Boutin, G. (2005). Recherche Qualitative. Lisboa: Instituto Piaget, 2005.

Martinez, N. Z. (2006). O papel da paternidade e a padrectomia pós-divórcio. Acesso em 11.10.2006, em www.pailegal.net/.

Mendes, R. (2007). A parentalidade experimentada no masculino: as vivências da paternidade. ISCTE: Centro de Investigação e Estudos de Sociologia.
Morin, E. (2005) Os setes saberes necessários à educação do futuro. São Paulo: Cortez / Brasília: UNESCO.

Pimentel, A. \& Franco, V. (2005). A Família em Tempos de Mudança. Revista do NUFEN (Belém). 3 (1), 47-56.

Pimentel, A., Frazão, E. R., \& Franco, V. (2007). Autopercepções da Paternidade. Em XIV INFAD: Nuevos Modelos Familiares. Necesidades Educativas, Mayores. International Journal of Developmental and Educational Psychology, Nr.1, Volumen 3, pp. 107-116. Badajoz - España: Edita.Asociación Nacional de Psicología de la Infancia y de la Adolescencia.

Pimentel, A. (2007). Da Criança ao adolescente. Em Adelma Pimentel (Org.), Universo Adolescente (pp. 17-25). Belém: Centro de Desenvolvimento da Adolescência.

Rohde, L.A., Wolf, A.L., Couto, A.H.F., Shansis. D.M., Shansis, F.M., Cunha, G.B., \& Lorenzon, S.F.S. (1991). A Função Paterna no Desenvolvimento do Bebê. Revista de Psiquiatria do Rio Grande do Sul, 13 (3), 127-135.

Symington, M. (2007). Guia American Express Portugal. Porto: Editora Civilização.

Suassuna, E. (2006). Um Olhar sobre a paternidade. Acesso em 11.10.2006, em www.pailegal.net/fatpar.asp?rvTextoId=11 06488039\&rvTextoRecenteTipo=(T).

Trindade, Z. A. (1998). Concepções de maternidade e paternidade: O convívio atual com fantasmas do século XVIII. Em Lídio de Souza, Maria de Fátima Q. de Freitas \& Maria Margarida P. Rodrigues (Orgs). Psicologia: Reflexões (Im) pertinentes (pp. 129-153). São Paulo: Casa do Psicólogo.

Wang, M.-L., Jablonski, B. \& Magalhães, A. S. (2006). Identidades masculinas: limites e possibilidades. Psicologia em Revista [online], 12 (19), 54-65. [Citado 11 outubro 2006] Disponível em: http://pepsic.bvs-psi.org.br/scielo.php?script=sci pdf\&pid $=$ S1677-11682006000100006\&lng $=$ pt\&nrm $=$ iso\&tlng $=\mathrm{pt}$.

Zoja, L. (2005). O pai: história e psicologia de uma espécie em extinção. São Paulo: Axis Mundi.

Adelma Pimentel - Fez Pós-doutorado na Universidade de Évora/ PT; é Doutora em Psicologia Clinica pela Pontifícia Universidade Católica de São Paulo; Vice-diretora da Faculdade de Psicologia da Universidade Federal do Pará (UFPA); Coordenadora de Extensão do Instituto de Filosofia e Ciências Humanas; Líder do Núcleo de Pesquisas Fenomenológicas (Diretório do CNPq); Pesquisadora do Mestrado em Psicologia da UFPA. Endereço Institucional: Universidade Federal do Pará / Instituto de Filosofia e Ciências Humanas. Rua Augusto Correa, s/n, Campus Básico, CEP: 66.075-110. Belém, Pará.Email: adelmapi@ufpa.br

Recebido em 12.06 .09 Primeira Decisão Editorial em 10.08.09 Segunda Decisão Editorial em 10.09.09 Aceito em 25.09.09 